CASE 45.-This was that of a young woman sent to me by Dr. E. P. Batler. It was a left hydronephrosis containing fire pints of urinous flaid. There was nothing of special interest in the operation or recovery, hence a description of them is unnecessary. The patient is now in very good health. CASE 46.-This was a very interesting one. The patient, a young woman aged thirty-four, had always been strong and bealthy till 1891, when she suffered much from constipation and from frequent calls to micturition, which always left her with a feeling that she had not emptied the bladder. She consulted Dr. Little of Dublin, and under his care improved, and he did not hear of her again till he was asked to see her in consultation and found that she had been under the care of Dr. Macan, who after the failure of a course of vesical injections bad opened and drained the right kidney through the loin. Before this operation she had rigors, high fever, and much pus in the urine; the latter was seen by the endoscope to be towing from the right ureter. In December, 1893, she called on Dr. Little on account of a discharging sinus in her side, complaining of pain in the rectum and in the meatus, which always came on about 11 A.M. Action of the bowels and passing urine would sometimes relieve her, but not always. After being in bed some hours at night she would have a free flow of arine, and then was better till the next day. Mr. Ball removed a mass of hæmorrhoidal tissue from the rectum, which gave relief while she remained in bed, but as soon as she was up again all ber troubles returned, and Dr. Little sent her to me. I found a sinus over the right kidney from which offensive pus was oozing, and she said that a little urine sometimes escaped also, but that there had been very little pus in the bladder urine since the operation. The evidence as to the presence of tubercle was conflicting. One expert said he had found the tubercle bacilli, another could find none. The kidney was very fixed, and I explained to the patient that the operation of removal of the kidney would be a specially dificalt and dangerons one in presence of this fetid sinus, bnt she said her life was so miserable that sbe would face anything to get better. 1 operated on March 29th, 1894, and with much difficulty entuleated the kidney, the adhesions being very dense and runing along the spine and great vessels. I began by carefully cleaning out the sinus and washing out the bidney with strong iodine solation, and dnring the operation I was very careful to avoid fouling the sac; immediately the kidney was out I flusbed the sac well out through the sinus with a 1 in 1000 corrosive sublimate lotion. My precantions were successful, for she had no fever after the operation, and practically no discharge from the sac, which I drained with a glass tube in front and a rabber one through the loin sinus. The ureter was not thickened and enlarged, as is usual with tubercle. I pinned it into the lower angle of the wound, and bad no further tronble with it. Convalescence was very satisfactory and rapid until she was up and abont, when there was some return of bladder discomfort; bat this soon passed cff, and when I last heard from ber she was in excellent health.

Remarks.-It is curious bow constantly renal cases are subjected to bladder treatment, and yet it is not difficult in most of them to elicit facrs from the patient which should, at any rate, make one suspect a renal origin, whereupon a caref al examination will reveal some renal abnormality, and the more severely the bladder is left alone the better for the patient. Tinkering the bladder is a very dangerous business in face of a ureter discharging pus. Many a patient bas told me that all the symptoms became serious after the simple passage of a sound into the bladder, and how much greater the risk must be when washings out and dilatations and digital ex plorations are practised may be imagined. Mischief spreads up the ureter with great difficulty when there is a constant flow of healthy acid urine down it, but when this arine is mixed with pus or blood, or both, it is a very different matter.

$$
\text { (To be continued.) }
$$

Football Casualties.--On Saturday last, during a match between the Derby County Reserve and Stoke Swifts teams, a player received a kick in the abdomen and was carried off the field to the pavilion, but the extent of his injuries was not fully ascertained.-On the same day, in a match between the Royal Military College and United Services teams at Sandhurst, one of the home three-quarters was "kicked on the head in stopping a rush." He was seen by two medical men who were present and was then taken to the College Hospital.

\section{ON THE ASSURANCE OF IMPAIRED LIVES, CHIEFLY WITH REFERENCE TO SPECIAL FORMS OF ASSURANCE. ${ }^{1}$}

By R. HINGSTON FOX, M.D.BRUX., MIDDICAL OFFICER TO THE UNITED KINGDOM TIEMPERANCE AND GENERAI PROVIDENT INSTITUIION, AND PHYSICIAN (FOR LONDON) TO THE FRIENDS' PROVIDEN'T INSTITUTION.

AN impaired life is a life of which we have evidence showing that the risk exceeds that of average lives, yet not so mach as to render it uninsurable. The evidence is derived from: 1. Family history: this may show chiefly two things(a) prevalence of some disease, especially tuberculosis or gout-inherited taint; and $(b)$ a tendency to die early-a "breaking-down age." 2. Personal history : facts indicating (a) attacks of disease, especially lung disease, rheumatism, gout, heart disease, or epilepsy ; and $(b)$ showing general weak health. 3. The present condition is much the most important factor: (a) habits and occupation; evidence of intemperance of any kind, insufficient fresh air and exercise, exposure to chill, malaria, \&c.; also various unhealthy occupations: (b) development and nutrition, inclading defect or excess of weight, ill-developed lungs, and premature age; (c) damage to organs and tissues, including the blood, langs, \&c.; and (d) disordered functions, circulatory, urinary, nervous, \&c. In most cases evidence from several of these classes will be combined.

How far is it possible to classify impaired lives? Three categories are suggested :--1. Lives in which increased risk is attached to the early part of the expectation period, with a probability that if that be surmounted the expectation will be lived out or exceeded. The typical example of this is the young life in good personal condition, but with a tuberculous family history. It is matter of common clinical observation that the liability to phthisis falls especially on the early years of adult life. The Registrar-General's returns are sometimes quoted to show that such mortality is nearly as great in later life. This is true in the strict sense-i.e., taking the ratio of deaths to persons living at those ages; bat if for insurance purposes we take 1000 persons living at the age of twentyone we find of course that the number surviving to subsequent ages is constantly diminishing. The mortality calculated on these diminishing numbers will show a more marked decrease in later years :-

\begin{tabular}{c|c|c|c}
\hline Age. & $\begin{array}{c}\text { Registrar-General. } \\
\begin{array}{c}\text { Deaths from } \\
\text { phthisis per mille } \\
\text { per annnm- } \\
\text { males. }\end{array}\end{array}$ & $\begin{array}{c}\text { Healthy males. } \\
\text { age entering at } \\
\text { surviving } \\
\text { (approximate). }\end{array}$ & $\begin{array}{c}\text { Estimated deaths } \\
\text { from phthisis per } \\
\text { mille per annum } \\
\text { of males entering } \\
\text { at age 21. }\end{array}$ \\
\hline $20-24$ yrs. & 3.09 & 1000 & 3.09 \\
$25-34$ " & 3.70 & 937 & 3.46 \\
$35-44$ " & 4.12 & 855 & 3.52 \\
$45-54, "$ & 3.86 & 752 & 2.90 \\
$55-64, "$ & 3.19 & 600 & 1.91
\end{tabular}

These figures refer of course to all forms of phthisis. But Dr. Reginald Thompson has shown ${ }^{2}$ that the mortality from inberited phthisis falls more markedly on early life than that from acquired phthisis, which is distributed throughout life. Hence the death-rate given above would show a greater decrease in the latter decades if deaths with a tuberculous family history were alone included. Further, the mortality from all canses greatly increases in later life, so that the proportion of phthisical deaths to total deaths will become less and less, ranging from 42 per cent. of all deaths at the ages 20-24, down to only 5.5 per cent. at the ages 55-64. That the risk in many cases of tuberculous inheritance attaches only to the earlier years of life may be illustrated by the history of two families: $(a)$ consisting of seventeen children, of whom ten died, nearly all from phthisis, at ages $1,16,16,20,20$, near 30,32 , about 36,38 , and 43 years, one from cancer at 57 (a daughter), and the remaining six lived on

Introduction to a discussion by the Life Assurance Medical Officers Association, March 27th, 1895. 
to $68,69,70,79,83$, and 91 years, of generally delicate healtb, but long.lived; (b) the danghter just mentiont as dying at 57 years married her cousin, who himself died at 69 from chronic lung trouble. They bad thirteen children : three died under 1 year ; five died, mostly from phtbisis, at $6,17,26$, 30 , and 30 years; one from preumonia at 39 ; and four are stiil living at ages 60 to 73 years. There are a few other conditions besides liability to phthisis which produce a similar increased risk. Diabetes has been known to attack several members of a family in young adult life. A more common liability is that to acute rheumatism, which is often associated with the susceptibility to the group of specific fevers-scarlet fever, diphtheria, and enteric fever. Certain families are especially liable to this entire group of diseases, ${ }^{3}$ and the increased risk of death therefrom falls chiefly on the earlier and middle decades of life. A family history showing an early "breaking-down age," irrespective of special disease, will also place a life in this category. To meet this bind of increased risk we need a form of policy which will especially guard the earlier part of the period of expectation of life. The risk is a diminisbing one. 2. A second category contains lives showing special risk at the other end of the expectation pericd. The ty pical instance of this kind of risk is found in a life entering yourg with an inherited taint of gout. When gouty disorders bave already shown themselves in a life entering in or after middle age the life belongs rather to the first category, the liability to death within a khort course of years beirg, as Dr. Symes Thompson bas recently shown, ${ }^{4}$ greater than is generally supposed. A family bistory showing some prevailing caure of death in old age-such as carcer-or a fersonal history of slight asthma or dyspepsia itcicates increased risk near the end of the expectation period without material addition to the risk at farlier ages. I am inclined to place here also cases of slight albuminuria with low arterial tension. The characteristic of this category is an increasing risk. It will be noted that it is mainly the evidence of family history which places a life in the two categories first described. In some cases this evidence is of great and obvious importance, but the experience of the Scottish UnderAverage Association of Iusurance Companies has shown that lives rated up on acconnt of family history bave had a much less mortality than those rated up for defective personal bealth. In most cakes there is, however, besides the bad family record, some elemert of perfonal weakness, and where, on the other hand, a proposer has every sign of rcbust health and good cevelopment, family history bas swall wejght. 3. The third and largest category includes lives with some geveral impairment of virality. This will increase the risk, no doukt, chiefly in the latter part of the expectation period, but also more or less during the whole of that period. The evidence of this impairment may be illustrated by the followirg: a generally unsatisfactory fawily history, showing valicus deaths in middle life; a personal history of weak health withont special illress; a personal condition of poor nutrition, arzmia, premature age, damage to organs, especially the heart; any cause that dimirishes the resisting power of the body to disease influences; hence unhealthy habits and occupations. Taking these lives as a group, the increased risk is represented by a shortened expectation period, and the form of assurance must provide for this general increase of risk. Mr. Chisholm has devised a diagram to show graphically the risk of death at varicus periods for a life entering at twenty y eai s : a curved line represents the normal death-rate for tach year of life, and this can be varied to represent the incresse of risk at any particalar epoch. 5 With regard to the special forms of assurance best adapted to meet these various risks, it may be objected that this is a question for the actuaries alone Yet surtly the medical officers of companies are ccnstantly advisiog recourse to this or that form of policy. And whilst it is for the actnaries to devise forms of insurance to meet the special risks which we can define, and to wcrk them out in detail on a sound financial basis, it is surely our part to understand that which they have devised, and to examine its applicability to the various risks with which we meet, so that our advice to the companies may be founded upon a full knowledge of the methods in use. Before going further allusion may be made to one guiding principle in the provisicn made for these risksviz., that as a rule all weak lives should be subjected to some

3 Brit. Med. Jour. 1889, vol. ii.. p. 586

5 Journal of the Institute of Actuaries, vol. xxy., y. 408. kind of extra rate, whether in the event they prove to be under or over the average length. It is surely no injustice that an impaired life should be thus charged, even if that particular life reaches or excec ds its expectation. I mention this because the contrary has been maintained. As American actuary (Mr. Fouse) writes that the correct principle is only to treat "those lives as under average which prove themselve to be so." I Is obvious that a very much heavier extra rate mast be put upon impaired lives if it is only to come into force in the $\in$ vent of their falling in early.

I propose now to pass briefly in review the chief forms of assurance in use in this country, with special reference to their applicability to the risks of impaired lives: 1 . The ordinary whole-life policy, with annual premium, about which it need only be said that it may fairly cover a considerable margin of risk. 2. T'he ordinary whole-life policy rated op in the manner usual in this country-i.e., by taking the lif at an assured age, say five, seven, or ten jears in advance 0 the real. (The practice of making small advances of one, two, perhaps even three years, to meet slight extra risks is I imagine, generally felt to be inexpedient.) This is a very convenient and straightforward method of dealing with in creased risks, and no doubt in the main works very well Investigaticns which have been made by various companie, such as the Eagle and the Lquity and Law Companies, have, I believe, generally shown that the advances imposed have abont or nearly met the extra mortality of impaired lives This may not be true of certain classes of risks, particulaily of gout, as shown by Dr. Symes Thompson and others, but appears to be true of all the risks taken in the aggregate This method of meeting increased risks has a somewhat unequal application to the different ages of life. Thus, in early adult life, wben the premium rates are low and increase very slowly, an advance of seven or tei years results in a comparatively small addition, and the loss to the cffice if death occurs early in the expectation period is scarcely lessened. On the other hand, at or after middle age an advance of seven or ten year becomes almost prohititive. If is important not to fix these advances by any mere "rule of thumb"; the use of the table of expectation of Jife affords a more scientific metbod, as one can form some idea of the shortening of the expectation period appropriate to the case, and then sfe to what advarce in years this may correspcnd. A simple advance, then treating the life as a little older than the real age, sfems fairly ro meet the third category of impaired lives, where there is a generally increased risk attaching to no special pericd. A typical condition is that of premature ageing When the risk attaches to the earlier years, I submit that form of advance which better protects the company against the risk should be adopted. And when the extra risk belong to the latter part of the expectation, a form of advance mose acceptable to the proposer can be found. The mortalit experience colle cted by the Institute of Actuaries in 1899 showed clearly that after the first five years from entry the mortality of impaired lives accepted for insurance was but little greater than that of bealthy lives. Thas, during the first five jears the mortality of diseased lives at ages twenty five to thirty.fcur was 62 per cent. higher than that of healthy lives, ard at sixty-five to seventy-four 25 per cent. higher: but after the five years had expired the percentage of increase ranged from but 29 to 16 per cent. This suggests that the risk of lives accepted at advanced rates really falls, in no inconsiderable proportion of instances, upon the early years after assarance. 3. A policy subject to temporary deduction from the sum assured ; otherwise, chargirg the policy with a diminishing lien or contingent debt. By this method, originally proposed by the late Mr. M. A. Black in 1861,7 and improved by Mr. W. M. Makeham in 1872,8 a deduction is made from the full value of the policy in the event of death occurring within a definite period, usually the expectation of life; a large deduction if the death occurs early, but gradually diminikirg until the end of the period, when it vanishes, and the policy is paid in full. The amount is calculated to be fouivalent in value to an advance of a given number of years, This method, which is explaived and commended in Dr. Pollock's and Mr. Chisholm's handbook, ${ }^{2}$ is referred to by Dr. Reginald Thompson as peculiarly applicable to cases in which a phthisical family history is present, and it certainly seems to provide against a risk attached to the early years of adult

6 On Insuring Under-Average Jives, by L. G. Fouse. 1892 8 Journal of Institute of Actuaries, 12th, 1891, p. 400. Jonmal of Institute of Actuaries, vol. xvii., p. 153 
life in a more satisfactory manner than any other in use. Take the case of a man entering at twenty-one years, of good personal condition, but with a family history of phthisis fatal at early ages. It is but little protection to the company to adrance his premium rate a fow years. In the aggregate of impaired lives the company may not lose, but is not the balance maintained by making the lives of other and less argent risk pay for his special risk? On the other hand, ench a proposer may fairly be expected to submit to a deduction of this kind as the penalty of his particular risk.

[To illustrate this matter Dr. Fox showed a table and chart exhibiting the loss to the company attaching to death at rarious ages under several different forms of policy, from which it appeared that the only method which met the risk of the early years after assurance was the deduotion policy. Ele continued:]

This is no donbt largely an actuarial question, yet it ceems to me that as medical officers we might do well to represent to our actuarial colleagues that there is a special class of risk which needs such a method as this to meet it adequately. The method is in use by several companios, but does not seem to be as well known as it deserves. It will be observed that this method of dealing with impaired lives is not in accordance with the rule submitted just now, that the extra rate should be of a nature to apply to all such lives whether they die early or later. The plea, however, is that to meet a special limited risk the rate should fairly be applied in the manner shown, and that it wonld not be just, to burden all who survive this special risk in early life and live, perhaps, to old age, as in the instances given, with a heavy cbarge. In adrocating the use of this form of policy it is not sug. gested that lives with a phthisical taint should be accepted more freely than is at present the practice, but only that they should be subjected to the conditions described. 4. The Nimited payments policy, under which the entire preminms are paid up in a fixed term of years-say, ten or twenty. A Sarge sum is accordingly received in the early part of the sexpectation period, and, if death occur prematurely, the loss is less than under the usual plan of spreading the premiums over the whole of life. This lessens the risk in the case of impaired lives, but it does not fully meet it, since the rates are calculated upon the experience of healthythat is, average-lives. It is not, therefore, proper to ase this form of assurance for lives of increased risk without moking an addition, excepting in cases of a slight character, in which the lessening of the risk may he considered to bring it within the margin of average risks. It is in cases with increased risk of death in the middle part of the expectation period that the limited payment policy is most useful, but, a small extra rate should be added. 5 The endowment policy. This is a very interesting form of policy, and one which esjoys a just and increasing popularity in this conntry. It is of importance in the present connexion since Dr. Glover Lyon has told us that it is largely used in the Tnited States, as I understand, without extra rating, for the assurance of under-average lives; but, as with the limited payment policy, so here the rates are calculated on average lives, and it cannot, therefore, be right to use the endowment policy without extra rating for impaired lives taken as a class. The large premiums reduce, of course, as in the former case, the loss to the office in the event of early death, and an actually smaller advance is needed than with whole life policies; this shonld be given in the form of a percentage addition. The special feature of an endowment policy, the term of which is almost always well within the expectation period, is that it cuts off the end of that period. Hence, as Dr. Pollock has told us, it roay be of the greatest uce for lives without suffioient stamina to carry them into old age, and it may be so applied as to cut the insurarce short at the breaking-down age. It is, in fact, especially usefnl for the case of an increasing extra risk herein contrasting with the deduction policy, which is stristly applicable to a decreasing risk (Makeham). For lives with a phthisical family history this method has, therefore, a very limited use. sirce it leaves the early years unprotected. A tendency to gout, on the other hand, is especially well met by an endowment policy, provided the proposer comes before us pretty earlo in life, and the term of the endowment is fixed so far within the espectation period as the probable shortening of the life may require. And I would suggest that slight degrees of albaminuria, with low blood tension, may be appropriately dealt with in this way. In such cases, if the personal condition is otherwise good, an extra rating does not seem needful. It is understood that the mortality experience of endowment policies is very favourable, no doubt in part owing to an unconscions selection amongst proposers. The endowment policy is, then, especially applicable to impaired lives of the recond category, and with an extra rating to those in the third category.

Finsbury-square, E.C.

\section{IMPACTION OF ENORMOUS GALL-STONE IN} THE LOWER PORTION OF THE ILEUM INTESTINAL OBSTRUCTION ; LAPAROTOMY; ENTEROTOMY;

\section{RECOVERY.}

\section{BY W. C. EVERLEY TAYLOR, F.R.C.P. EdIN.,}

SURGLON TO THE SCARBOROUGI HOSPITAL.

TuIs case is of interest on account of the comparative rarity of intestinal obstruction being caused by gall-stone, the enormous size of the concretion, the prolonged period the patient was on the verge of complete obstruction, and the remarkable recovery after so severe an illness.

On April 3id, 1894, a woman aged fifty-six years, residing about two miles from Scarborough, sent for Dr. Rust and royself. She gave my colleague a history of continuous vomiting for a period of thirty-six hours. She seemed very exhausted. There was no evidence of organic disease or error of diet to account for it. She stated that she had been in perfect health for thirteen years, never having needed medical attendance since 1880, when Dr. Taylor opened a very large abscess in the thigh. Predigested food was ordered and a bypodermic injection of a quarter of a grain of morphia ice, \&s. For the next forty-eight hours the vomiting was nearly continuous and nourishment of any kind was only retained for a few minutes. On the 5 th at 8 P.M. I sa. her. She was not so collapsed as the continuous vomiting, now lasting two days, would have led one to expect. On making a carefal examination of the abdomen a little below the apex of the ninth rib a rounded swelling, slightly movable and dull on percussion, was discovered. There was no evidence of hernia at any of the hernial openings. There was no evidence of disease in any organ, nor did the examination of the rectum reveal anything; flatus had been passed and a small motion. The next day the condition of vomiting remained; feeding by the mouth was stopped, and nutrient suppositories were ordered every four hours. A careful examination by Dr. Godfrey and myself failed to discover the ronuded swelling detected on the previous day. For the next five days all food by the mouth was prohibited, and peptonised enernata and nutrient suppositories were adminis. tered. Only a little water was allowed by the mouth. While this line of treatment was pursued there was no retching or nausea, and fldtus was passed every day. On April 14th deep palpation in the left iliac region gave a sensation of localised hardness and resistance over a limited area. Every day the patient said she felt flatus passing through the intestines, which was expelled, and at no time was the vomiting of a stercoraceous character. Water, when given by the mouth was retained, but any other kind of fluid nourisbment returned unchanged. The patient volunteered a statement that one night in December, 1893, she had great pain over the site of the gall-bladder, which had kept ber awake, that Dr. Scarth had seen her, and had said she had gall-stone. She had forgotten all about this until now, although previously questioned on this matter. On April 17th Dr. Caff saw her in consultation, and the question of the escape of a large gall stone by alceration from the gall-bladder into the intfstine was suggested as an explanation of the symptoms. It was decided to wait and not operate until the symptoms of obstruction became more acute. During the next few days the palse and the temperature were normal and a little peptonised milk was given by the mouth which was irnmediately vomited. On April 24th it was decided to remove the patient into Scarborongh, as it was felt that the necessity for an abdominal section might arise at any time. She bore the journey well. On April 27/h the vomiting became stercoraceous, the temperature rose to $100^{\circ} \mathrm{F}$. and the pulse to 120, the abdomen became distended, and no flatus had been passed for thirty-six bours, so abdominal section was decided upon. A median incision was made. It was decided to 